\title{
LIVE BODY WEIGHT PREDICTION IN HAIR GOATS BY APPLICATION OF FUZZY LOGIC
}

\author{
AMEen, A. A. - MiKAIL, N.* \\ Department of Animal Science, Faculty of Agriculture, Siirt University, Siirt, Turkey \\ (phone:+90-484-212-1111/2818; fax: +90-484 254-2057) \\ *Corresponding author \\ e-mail: naziremikail@ siirt.edu.tr; phone:+90-484-212-1111/2818; fax: +90-484 254-2057
}

(Received $4^{\text {th }}$ Jul 2018; accepted $8^{\text {th }}$ Oct 2018)

\begin{abstract}
The aim of this study is to try to develop fuzzy expert system for predicting live body weight in hair goats. As material, 81 hair goats grown in Siirt Province, Turkey were used. A fuzzy expert system was designed using heart girth, body depth and body length measurements of the animals. Fuzzy Logic Toolbox of MATLAB Software was used for fuzzy expert system development. The Mamdani inference method was used as inference method and the Centroid method was chosen as the defuzzification method. A correlation $r=0.95$ was found between the live body weight predicted by the developed system and the live body weight data obtained by actual weighing. The determination coefficient of the model was calculated as $\mathrm{R}^{2}=0.90$. As a result, we can say that fuzzy expert systems have better results in livestock with uncertainties and incomplete data and the development of these kinds of systems in the future is recommended.
\end{abstract}

Keywords: fuzzy sets, expert system, hair goat, live body weight, body measurements

\section{Introduction}

Regression models are generally used to predict prospective yield in animal breeding, or to estimate data that are difficult to measure with data that are measured more easily. The data must provide some assumptions to apply regression models (Graybill and Iyer, 1994). However, data in real life do not always meet these requirements. Instead of conventional statistical analysis, fuzzy logic models based on fuzzy set theory are more appropriate for such data. Fuzzy Logic (FL) approach was introduced in an article published by Lotfi Zadeh from University of California, Berkeley in 1965. Since then, fuzzy logic can be defined as a solid mathematical model set to explain and work with uncertainties. As it is known, statistics and probability theories work with certainties rather than uncertainties, however, the world of human is laden with vagueness. Therefore, mankind has been required to work with uncertainties to develop the ability of reasoning. The most significant feature of fuzzy sets is its capability to model verbal and digital information and data containing uncertainties concurrently in closest way to the human brain. Expert systems based on fuzzy logic play a role of consultant, expert while facilitating the works of breeders. There are some expert systems that have been developed in animal husbandry (Ferreira et al., 2007; Alizadeh et al., 2008; Jampour et al., 2011; Agbonifo and Ajayi, 2012; Menesatti et al., 2014; Dağ et al., 2015).

An expert system (ES) is one of the programming methods that, like expert people, can decide, so people aiming to solve these problems by modeling (Nabiyev, 2005). The purpose of an expert system is to solve problems that can be solved by a human expert. An expert system can be expressed as a transition from data processing to knowledge processing. In data processing, when the database is processed efficiently depending on 
an algorithm, in information processing for example heuristic (experience-based) method issues rules and facts which consists of the knowledge base is efficiently processed without being bound by any algorithm (Allahverdi, 2002).

One of the important issues in animal husbandry is to provide body weight data from the animal without stressing it. It is possible to estimate the animal's live body weight by using body measurements. For this purpose varied works have been done with conventional methods (Keskin and Dağ, 2006; Pesmen and Yardimci, 2008; Sowande and Sobola, 2008; Abegaz and Awgichew, 2009; Tadesse and Gebremariam, 2010; Y1lmaz et al., 2012; Iqbal et al., 2014).

The number of goats in Turkey is close to the number of goats in whole Europe. Figure 1 reveals how important goat breeding is in Turkey (FAOSTAT, 2016).

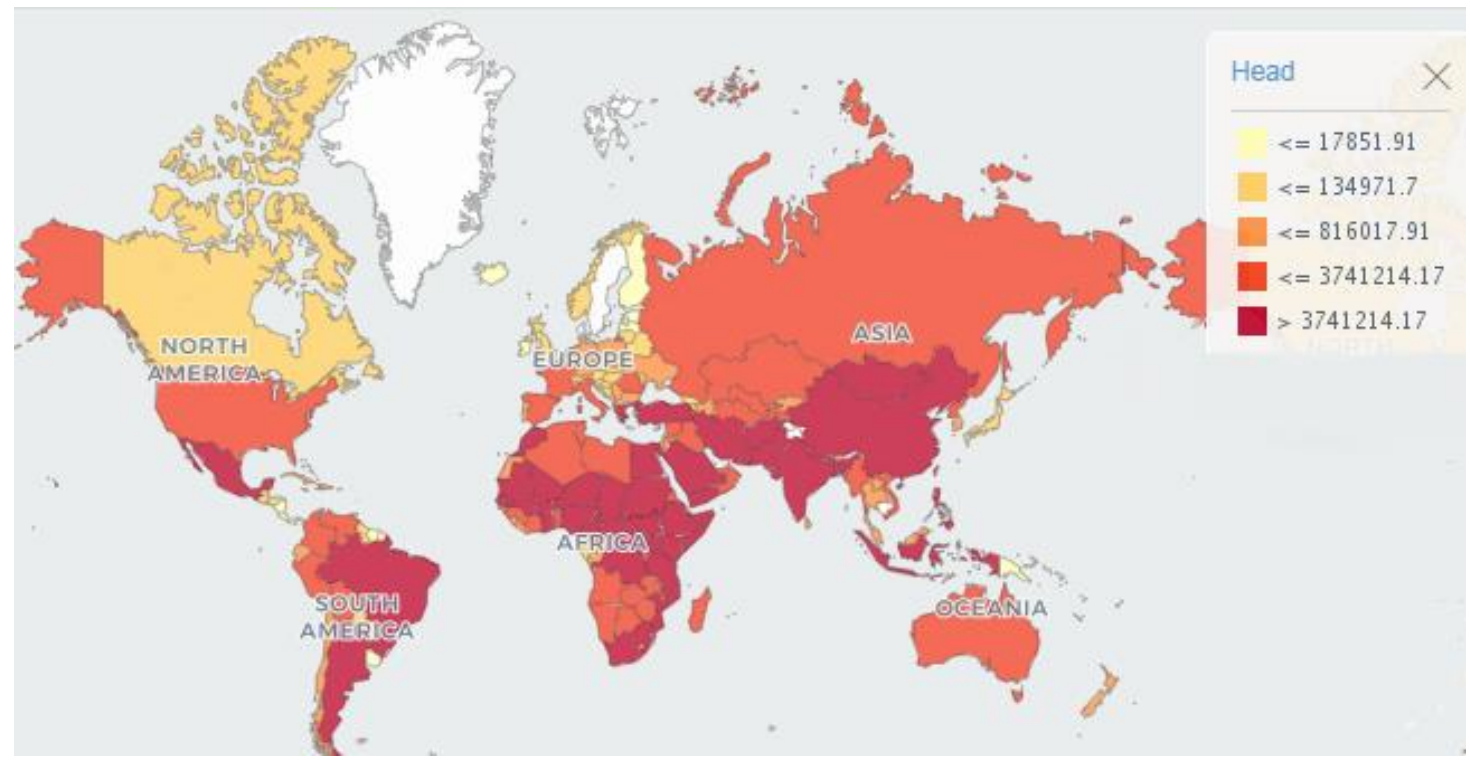

Figure 1. Production of goats by country (Average 1994-2016)

The objective of livestock is to maintain and even to increase profitability. For this purpose, fuzzy expert systems (FES) can help the farmers to achieve their goals.

In the current study FES and some applications in livestock were introduced and a sample FES design for live weight prediction in hair goats was developed.

\section{Materials and Methods}

\section{Material}

The material of the study was provided from a private farm in Siirt Province, Turkey. The data were collected from 81 female hair goats. The Hair goat, Turkish Native Black Hair or Anatolian Black (Mason, 1996) is the most numerous breed and probably accounts numerically for more than 90 percent of the national goat flock. They are part of the Syrian type and while usually black they are sometimes seen in brown, gray or pied. It is the hardest of all Turkish goat resources, well adapted to climatic extremes, to rough and rocky terrain, to poor feed and resistant to local diseases and to managerial indifference. This is mainly a meat goat with a low milk yield and low growth rate. (Olfaz et al., 2011; Y1lmaz et al., 2012). 
Heart girth (HG), Body depth (BD), Body length (BL) and Live body weight (LBW) parameters were recorded after 8 hours of feed restriction. The age of the goats ranged from 10 to 36 month. Body measurements were taken by a tape measure (Fig. 2) and body weight was taken using a digital scale (Chacon et al., 2011):

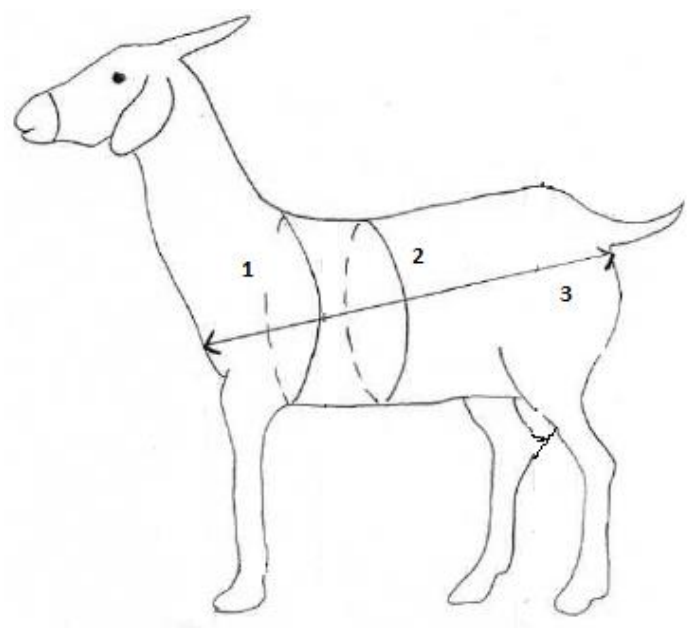

1. Body depth (BD)

2. Heart girth (HG)

3. Body length (BL)

Figure 2. Body measurements of female goats (Chacon et al., 2011)

1. Body Depth: For this parameter, the height between the very end of the goat's front leg and its back was measured. The stability of the goat is very important during these measurement processes.

2. Heart Girth: is a circumferential measure taken around the chest just behind the front legs and withers. During the measurement, the animal should be kept stable and the accuracy of the reading was double checked.

3. Body Length: refers to the distance from the base of the ear to the base of the tail. It can also be measured as the distance from the base of the tail to the base of the neck (first thoracic vertebrae), or to the front of the chest or to the tip of the nose (Mahmud et al., 2014).

4. Body Weight: The goat which body parameters were measured was weighed according to its body weight by digital scale and the values were noted down.

Husbandry system influences body measurements. Development of animals can be influenced by management and feeding. HG and BD are not significantly influenced by husbandry system (Riva et al., 2004).

\section{Method}

A typical process in developing the fuzzy expert system incorporates the following steps (Negnevitsky, 2005):

1. Specify the problem and define linguistic variables.

2. Determine fuzzy sets.

3. Elicit and construct fuzzy rules.

4. Encode the fuzzy sets, fuzzy rules and procedures to perform fuzzy inference into the expert system.

5. Evaluate and tune the system. 


\section{Linguistic variables}

Input and output crisp numerical data were fuzzified and converted into linguistic variables (Table 1).

Table 1. Linguistic terms used for the body measurements

\begin{tabular}{c|c|c}
\hline Heart Girth range (cm) & Linguistic terms & Membership functions \\
\hline $74-80$ & Short & trapezoidal \\
$78-85$ & Medium & triangular \\
$83-90$ & Long & triangular \\
$88-96$ & Very Long & trapezoidal \\
\hline Body Depth range (cm) & Linguistic terms & Membership functions \\
\hline $73-80$ & Short & trapezoidal \\
$78-90$ & Medium & triangular \\
$88-95$ & Long & triangular \\
$93-105$ & Very Long & trapezoidal \\
\hline Body Length range (cm) & Linguistic terms & Membership functions \\
\hline $56-65$ & Short & trapezoidal \\
$63-70$ & Medium & triangular \\
$68-74$ & Long & triangular \\
$72-82$ & Very Long & trapezoidal \\
\hline Live Body Weight range $(\mathbf{k g})$ & Linguistic terms & Membership functions \\
\hline $22-32$ & Low & trapezoidal \\
$30-42$ & Medium & triangular \\
$39-48$ & High & triangular \\
$45-57$ & Very High & trapezoidal \\
\hline
\end{tabular}

\section{Fuzzy sets}

Triangular and trapezoid membership functions were set for the fuzzy variables as inputs and output. The fuzzy sets and membership functions for each of the 3 input variables and 1 output variable were determined (Figs. 3-6).

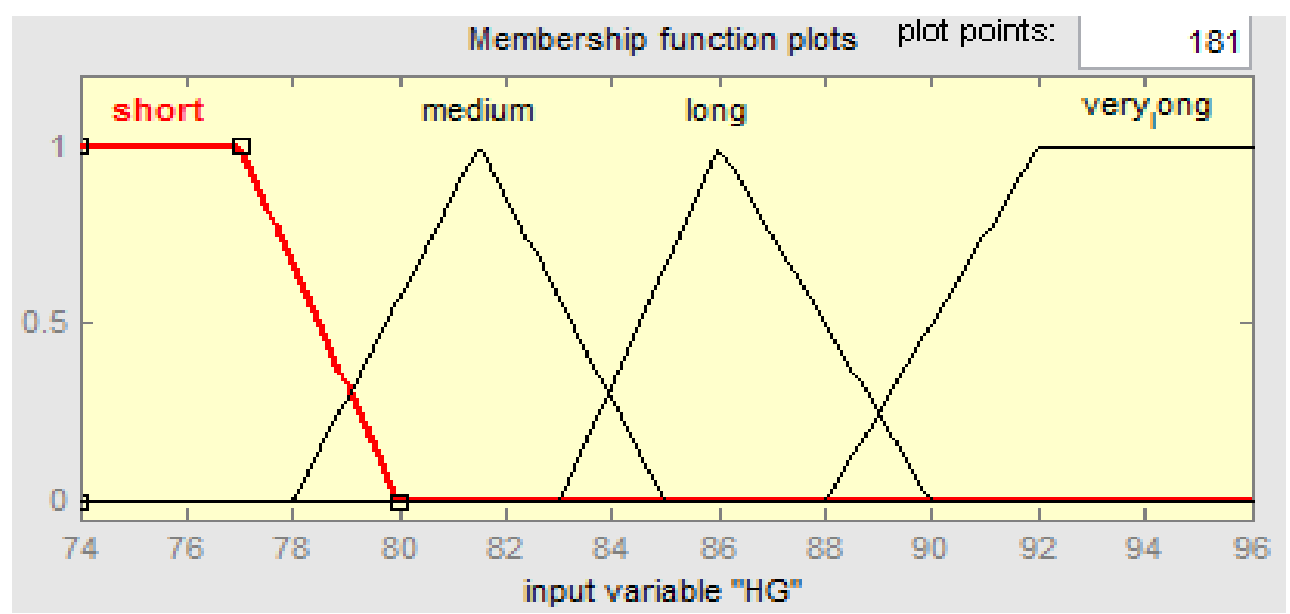

Figure 3. Membership function graphic for $H G$ 


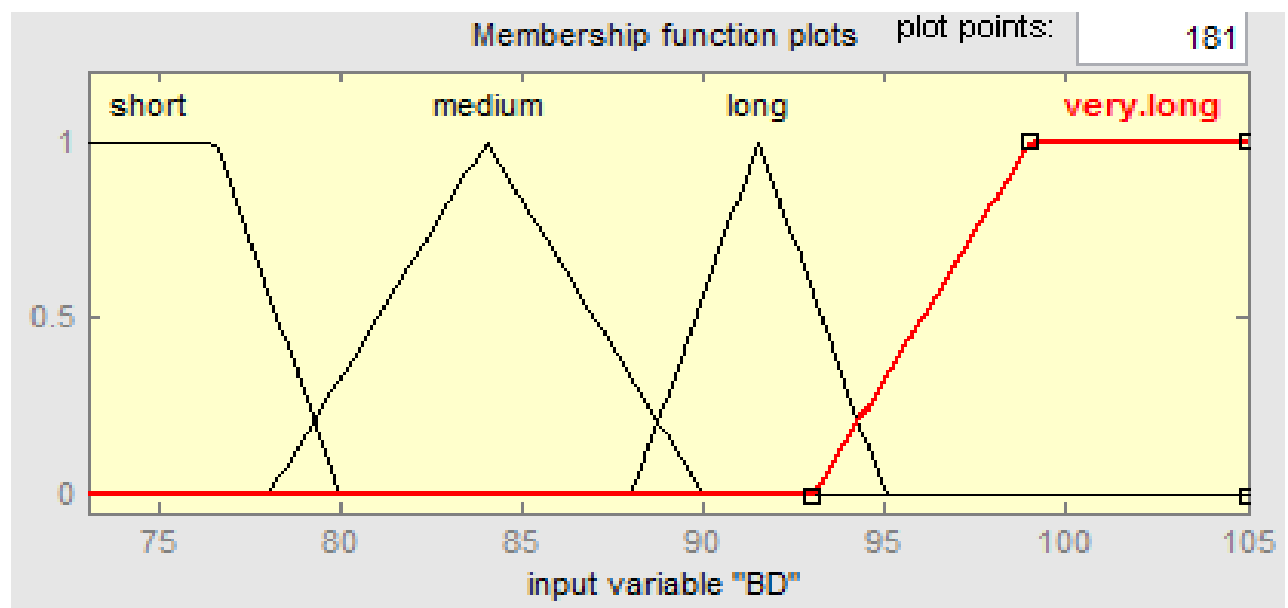

Figure 4. Membership function graphic for $B D$

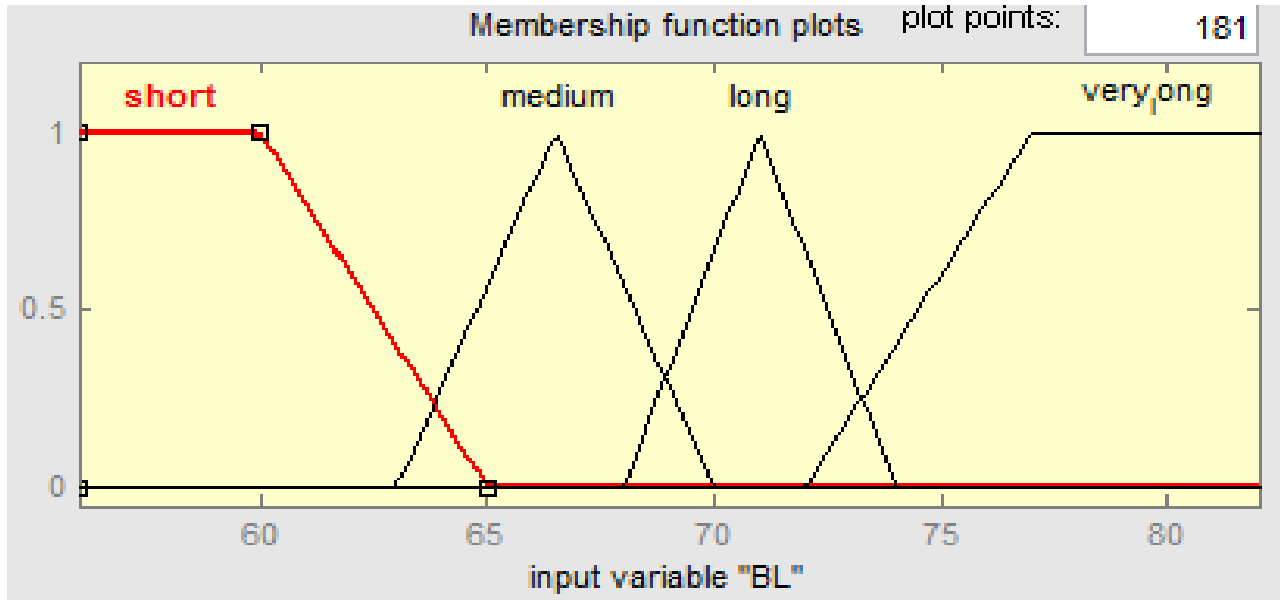

Figure 5. Membership function graphic for $B L$

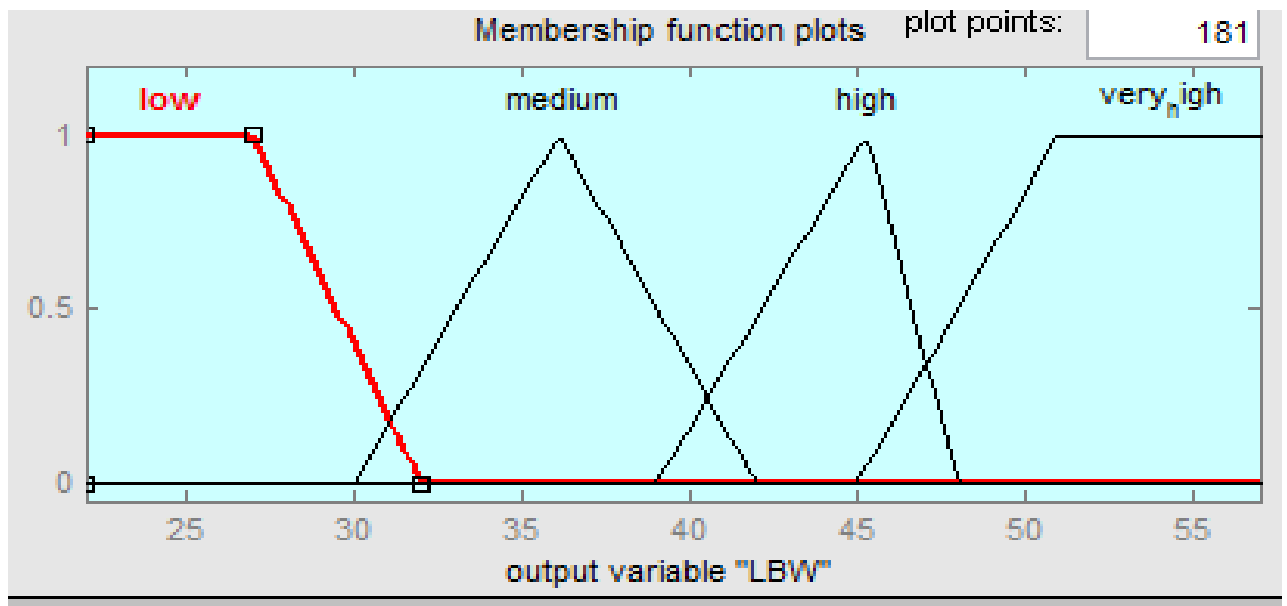

Figure 6. Membership function graphic for $L B W$ 


\section{Fuzzy rules}

The system knowledge base was constituted from 29 rules. Some of the rules are given in the Table 2 .

Table 2. Rule sets for the FES

\begin{tabular}{c|cccccccc}
\hline Rule No & & HG & & BD & & BL & & LBW \\
\hline 1 & IF & Short & AND & Medium & AND & Short & THEN & Low \\
$\ldots$ & & & & & & & \\
6 & IF & Medium & AND & Medium & AND & Medium & THEN & Medium \\
$\ldots$ & & & & & & & & \\
10 & IF & Medium & AND & Very long & AND & Long & THEN & High \\
$\ldots$ & & & & & & & & \\
16 & IF & Long & AND & Medium & AND & Medium & THEN & High \\
$\ldots$ & & & & & & & & \\
23 & IF & Very long & AND & Very long & AND & Very long & THEN & Very high \\
$\ldots$ & & & & & & & & \\
29 & IF & Very long & AND & Long & AND & Very long & THEN & High \\
\hline
\end{tabular}

For example, Rule 10 from the table can be explained as follows: If HG is medium and BD is very high and BL is long then LBW is high.

\section{Inference method}

Mamdani inference method was chosen as the inference method (Mamdani and Assilian, 1975). Due to Mamdani max - min method is applied, the $\lambda$ accuracy ratios for each rule are determined.

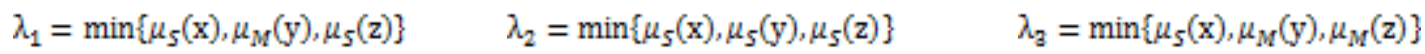

$$
\begin{aligned}
& \lambda_{4}=\min \left\{\mu_{5}(\mathrm{x})_{i} \mu_{L}(\mathrm{y}), \mu_{M}(\mathrm{z})\right\} \quad \lambda_{5}=\min \left\{\mu_{M}(\mathrm{x}), \mu_{M}(\mathrm{y}), \mu_{L}(\mathrm{z})\right\} \quad \lambda_{6}=\min \left\{\mu_{M}(\mathrm{x})_{i} \mu_{M}(\mathrm{y}), \mu_{M}(\mathrm{z})\right\}
\end{aligned}
$$

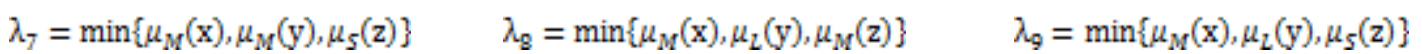

$$
\begin{aligned}
& \lambda_{10}=\min \left\{\mu_{M}(\mathrm{x})_{,} \mu_{V L}(\mathrm{y}), \mu_{L}(\mathrm{z})\right\} \quad \lambda_{11}=\min \left\{\mu_{M}(\mathrm{x}), \mu_{S}(\mathrm{y}), \mu_{M}(\mathrm{z})\right\} \quad \lambda_{12}=\min \left\{\mu_{M}(\mathrm{x})_{,} \mu_{S}(\mathrm{y}), \mu_{L}(\mathrm{z})\right\} \\
& \lambda_{19}=\min \left\{\mu_{M}(\mathrm{x})_{t} \mu_{L}(\mathrm{y}), \mu_{L}(\mathrm{z})\right\} \quad \lambda_{14}=\min \left\{\mu_{L}(\mathrm{x})_{t} \mu_{L}(\mathrm{y})_{i} \mu_{M}(\mathrm{z})\right\} \quad \lambda_{15}=\min \left\{\mu_{L}(\mathrm{x})_{i} \mu_{M}(\mathrm{y})_{i} \mu_{5}(\mathrm{z})\right\}
\end{aligned}
$$

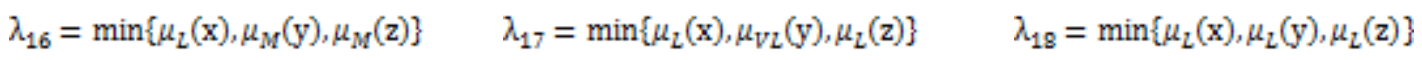

$$
\begin{aligned}
& \lambda_{19}=\min \left\{\mu_{L}(\mathrm{x})_{i} \mu_{V L}(\mathrm{y}), \mu_{M}(\mathrm{z})\right\} \quad \lambda_{20}=\min \left\{\mu_{L}(\mathrm{x})_{i} \mu_{V L}(\mathrm{y})_{*} \mu_{S}(\mathrm{z})\right\} \quad \lambda_{21}=\min \left\{\mu_{L}(\mathrm{x})_{v} \mu_{M}(\mathrm{y})_{i} \mu_{L}(\mathrm{z})\right\} \\
& \lambda_{22}=\min \left\{\mu_{V L}(\mathrm{x})_{i} \mu_{V L}(\mathrm{y})_{i} \mu_{L}(\mathrm{z})\right\} \quad \lambda_{2 \mathrm{a}}=\min \left\{\mu_{V L}(\mathrm{x})_{i} \mu_{V L}(\mathrm{y})_{i} \mu_{V L}(\mathrm{z})\right\} \quad \lambda_{24}=\min \left\{\mu_{V L}(\mathrm{x})_{i} \mu_{V L}(\mathrm{y})_{i} \mu_{M}(\mathrm{z})\right\}
\end{aligned}
$$

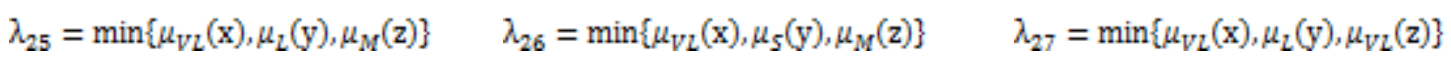

$$
\begin{aligned}
& \lambda_{28}=\min \left\{\mu_{V L}(\mathrm{x})_{s} \mu_{L}(\mathrm{y})_{i} \mu_{L}(\mathrm{z})\right\} \quad \lambda_{29}=\min \left\{\mu_{\mathrm{VL}}(\mathrm{x}), \mu_{L}(\mathrm{y}), \mu_{\mathrm{VL}}(\mathrm{z})\right\}
\end{aligned}
$$

\section{Performance criteria}

The estimated performance was calculated with Mean Percentage Error (MPE), Mean Absolute Percentage Error (MAPE), Determination coefficient $\left(\mathrm{R}^{2}\right)$, Root Mean Squared Error (RMSE). The results of FES predicted LBW were compared with the actual weighed values (Taşdemir et al., 2011). 


$$
\begin{aligned}
M P E & =\frac{\sum_{i=1}^{n} \frac{Y_{i}-Y_{i}}{Y_{i}}}{n} \times 100 \% \\
M A P E & =\frac{\sum_{i=1}^{n}\left|\frac{Y_{i}-Y_{i}}{Y_{i}}\right|}{n} \times 100 \% \\
R^{2} & =\frac{\sum_{i=1}^{n}\left(Y_{i}-\bar{Y}\right)^{2}}{\sum_{i=1}^{n}\left(Y_{i}-\bar{Y}\right)^{2}} \\
R M S E & =\sqrt{\frac{\sum_{i=1}^{n}\left(Y_{i}-\bar{Y}\right)^{2}}{n}}
\end{aligned}
$$

where, $\mathrm{Y}_{\mathrm{i}}$ - observed value, $\widehat{Y}_{\mathrm{u}}-$ predicted value, $\bar{Y}$ - Arithmetic mean, $\mathrm{n}-$ the total number of observations.

\section{Results and Discussions}

Descriptive statistics concerning body measurements and LBW of hair goats are shown in Table 3. Correlation coefficients between body measurements and live body weight are shown in Table 4.

Table 3. Descriptive statistics of the obtained data

\begin{tabular}{c|c|c|c|c}
\hline Morphological Traits & $\mathbf{N}$ & Mean $\pm \mathbf{S}$ & Minimum & Maximum \\
\hline Heart Girth $(\mathrm{cm})$ & 81 & $85.84 \pm 5.605$ & 74 & 96 \\
Body Depth $(\mathrm{cm})$ & 81 & $88.43 \pm 7.586$ & 73 & 105 \\
Body Length $(\mathrm{cm})$ & 81 & $67.64 \pm 4.293$ & 56 & 82 \\
Live Body Weight $(\mathrm{kg})$ & 81 & $39.16 \pm 7.131$ & 22.40 & 56.60 \\
\hline
\end{tabular}

Table 4. Correlation coefficients between body measurements and LBW

\begin{tabular}{c|c|c|c}
\hline & LBW & HG & BD \\
\hline HG & $0.852^{* *}$ & & \\
BD & $0.767^{* *}$ & $0.764^{* *}$ & $0.650^{* *}$ \\
BL & $0.776^{* *}$ & $0.744^{* *}$ & \\
\hline
\end{tabular}

$* *: \mathrm{p}<0.01$

The general structure of the developed FES is shown in Figure 7. 


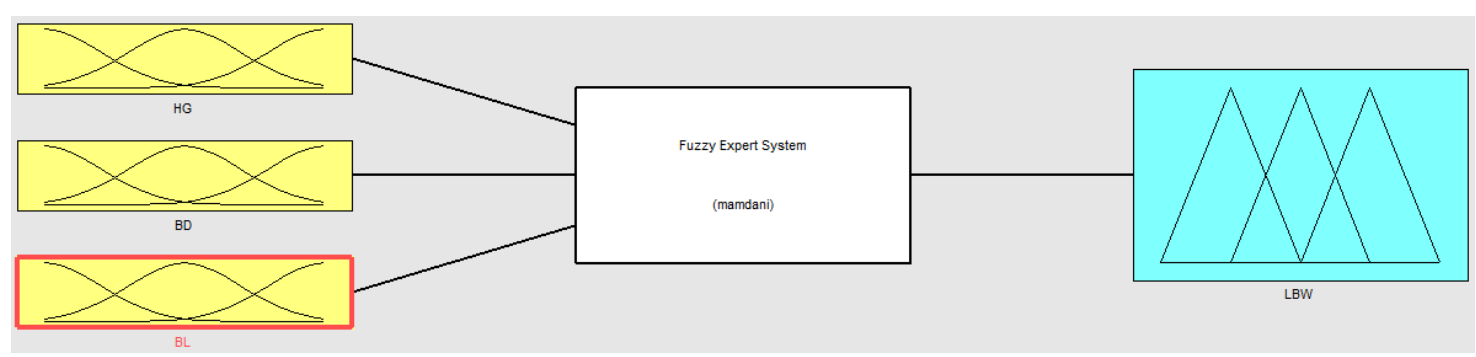

Figure 7. Structure of the developed FES

Three dimension graphics explaining the FES are shown in Figure 8.

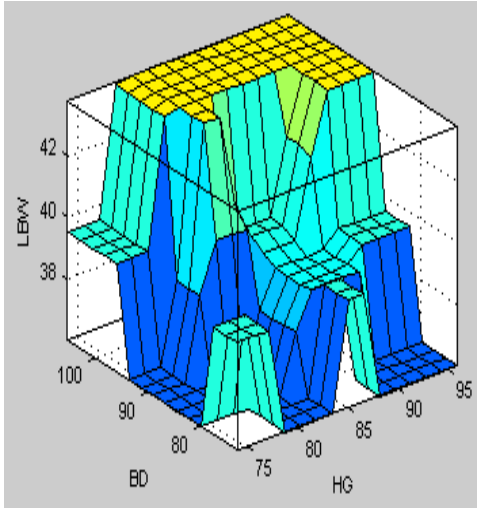

(a)

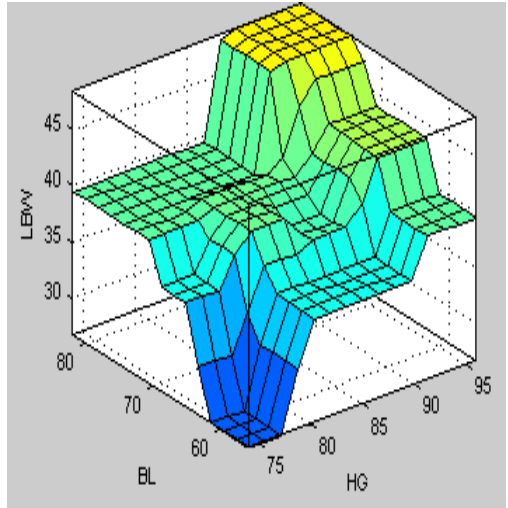

(b)

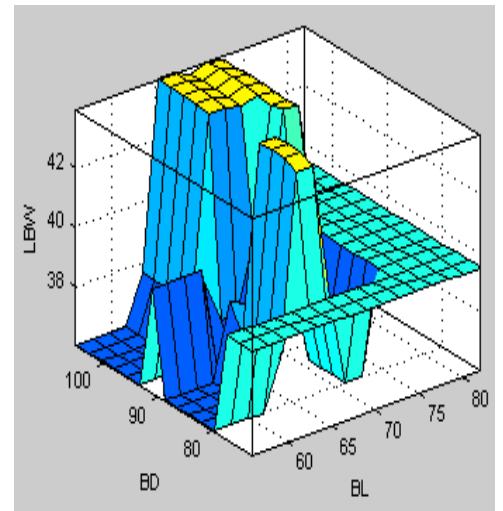

(c)

Figure 8. $3 D$ representation of $L B W(a)$ by $B D$ and $H G$; (b) by $B L$ and $H G$; (c) by $B D$ and $B L$

In the defuzzification process, crisp outputs were obtained by using the Centroid method according to the degree of accuracy. For example, $43.8 \mathrm{~kg}$ LBW was achieved in the developed fuzzy expert system in response to $95 \mathrm{~cm} \mathrm{HG}, 95 \mathrm{~cm}$ BD and $70 \mathrm{~cm}$ BL. The actual weight of this animal was $43.6 \mathrm{~kg}$. The fuzzy expert system result obtained for these inputs is given in Figure 9.

For the inputs $95 \mathrm{~cm} \mathrm{HG}, 95 \mathrm{~cm}$ BD and $70 \mathrm{~cm}$ BL just Rule No 23 was fired. In another example, the following measurements of the animal: $\mathrm{HG}$ is $85 \mathrm{~cm}$, BD is $86 \mathrm{~cm}$ and $\mathrm{BL}$ is $64 \mathrm{~cm}, \mathrm{LBW}=39.9 \mathrm{~kg}$ were achieved from the developed fuzzy expert system. The fuzzy expert system result obtained for these values is shown in Figure 10. For these inputs 3 rules was fired at the same time. Rule 15 and Rule 16 will be fired at the same time. LBW for Rule 15 is Medium, for Rule 16 is High. In this case, the inference will be calculated as the maximums of the accuracy grades of two fired rules:

Rule 15:

$$
\lambda_{15}=\min \left\{\mu_{L}(x), \mu_{M}(y), \mu_{S}(z)\right\}=\min \{0.5,0.8,0.2\}=0.2
$$

Rule 16:

$$
\lambda_{16}=\min \left\{\mu_{L}(x), \mu_{M}(y), \mu_{M}(z)\right\}=\min \{0.5,0.8,0.2\}=0.2
$$

$\lambda=\max \{0.2,0.2\}=0.2$

Then using Centroid method we can calculate the BWL as $39.9 \mathrm{~kg}$. 


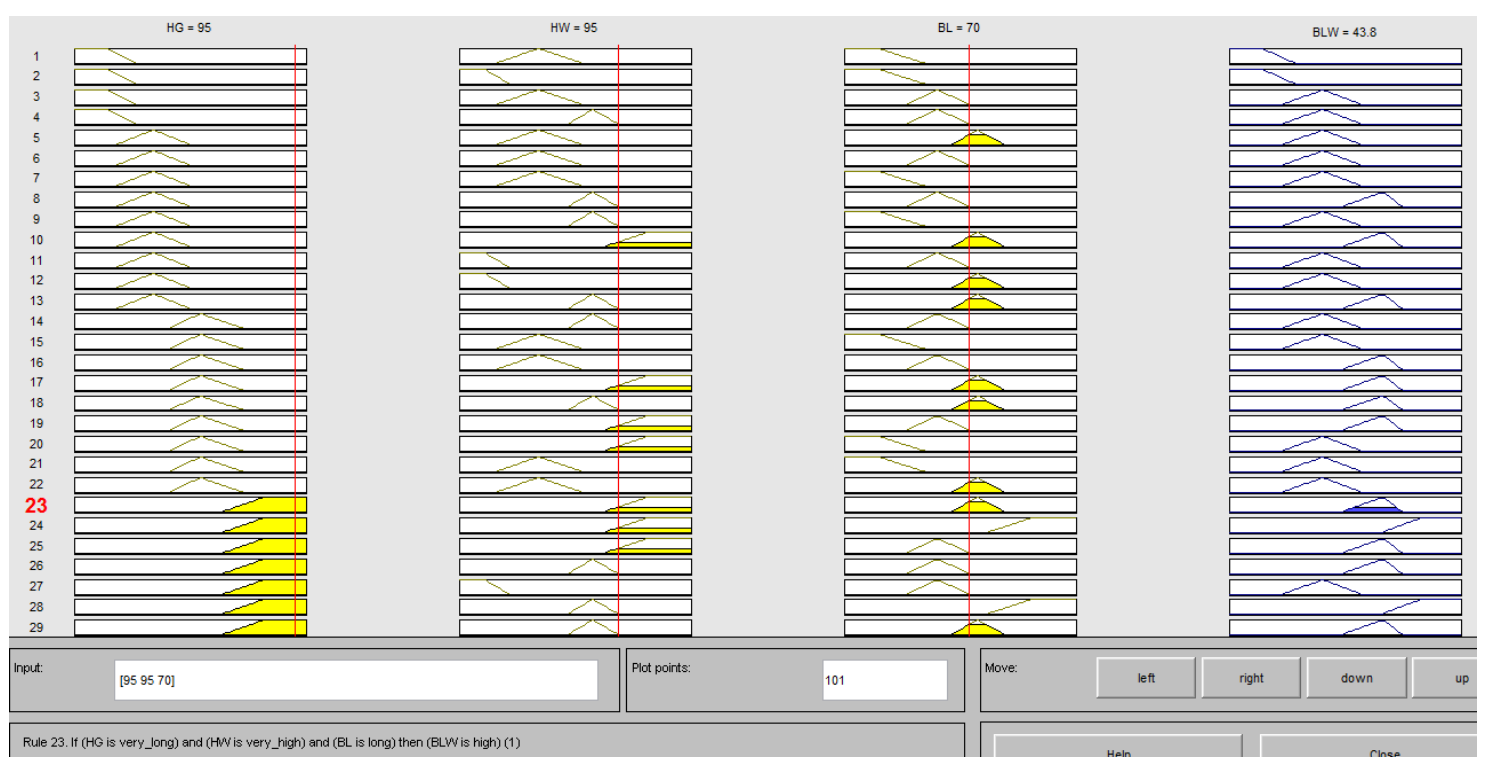

Figure 9. Result of FES

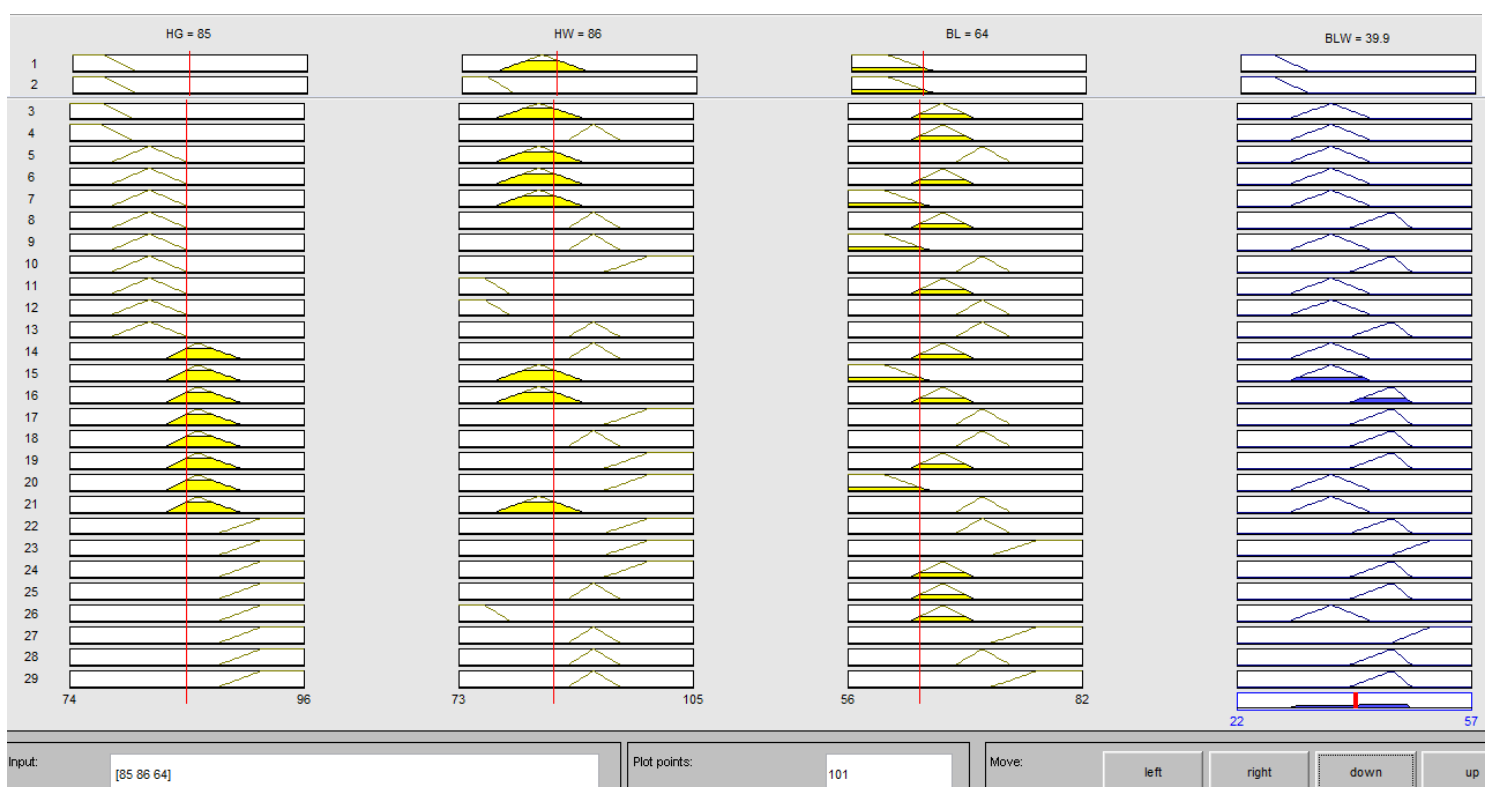

Figure 10. Case, where two rules are fired at the same time

After performing this simulation for all goats, it was possible to compare values obtained from FES with the weighed LBW (Fig. 11).

Pearson correlation coefficient between the actually and predicted data calculated as 0.95 , which represents a high positive correlation between these sets and indicates that the proposed method is suitable for the LBW prediction (Fig. 12). 


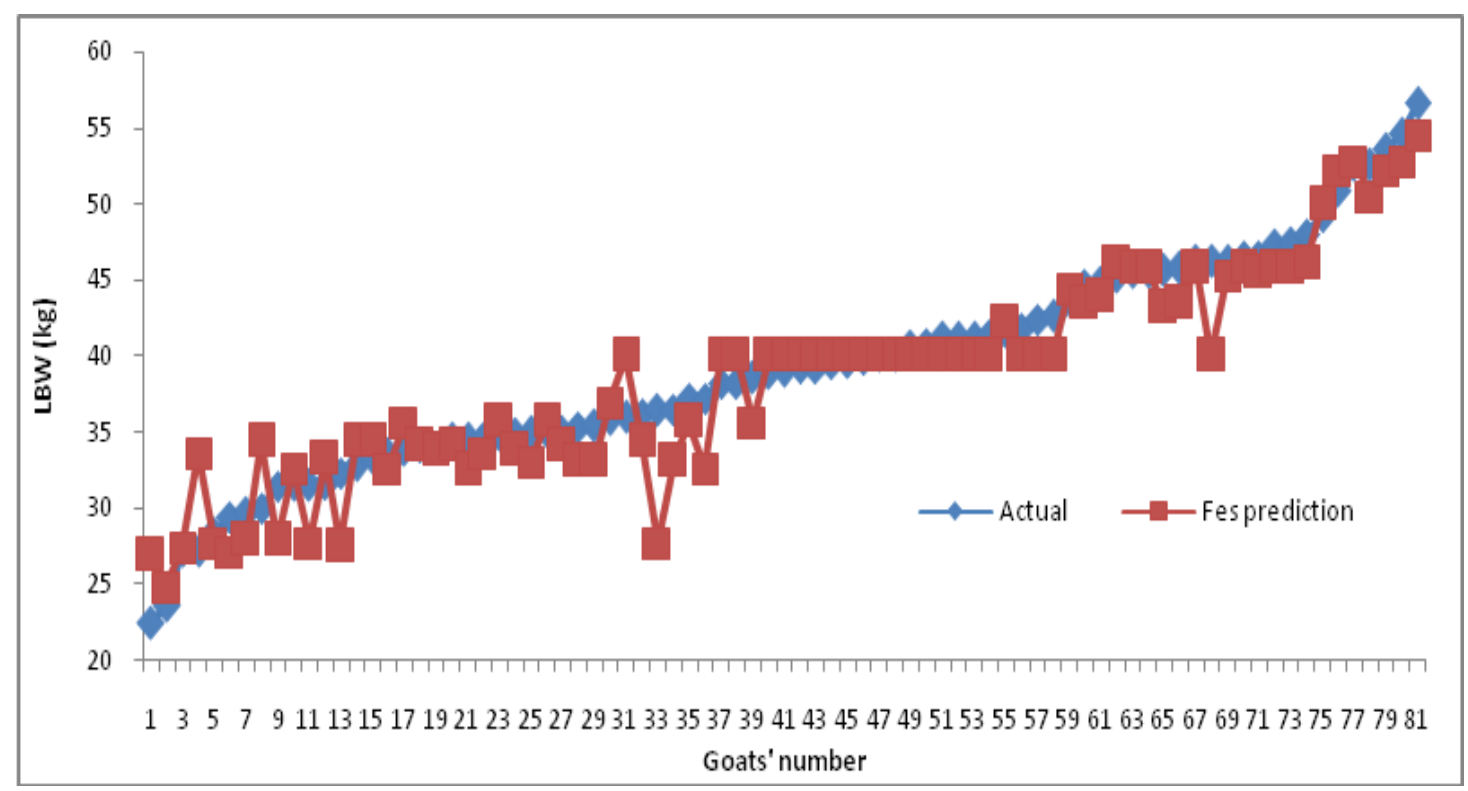

Figure 11. Comparison of Actual and FES predicted LBWS

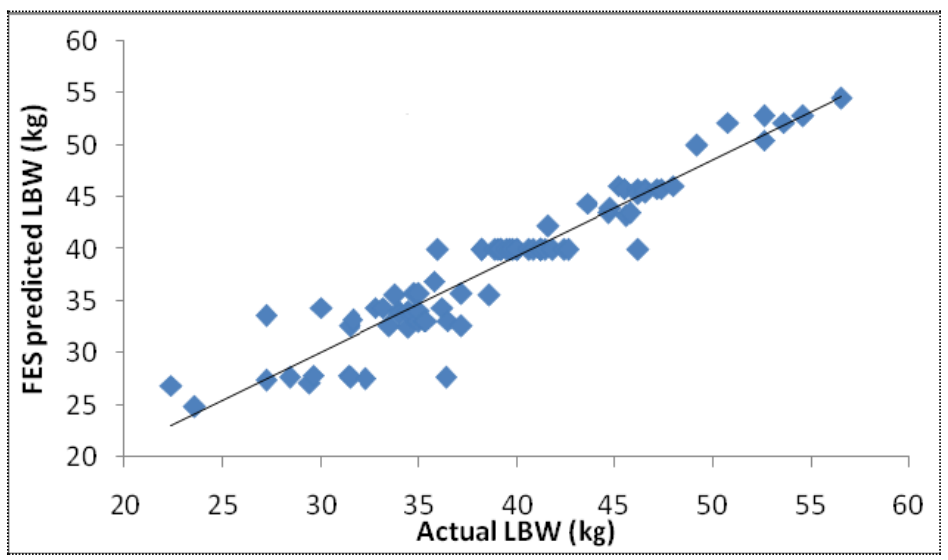

Figure 12. Correlation between Actual and FES predicted LBWs

Determination coefficient of the model was calculated as $90 \%$. The MPE, MAPE and RMSE values calculated as, 1.31, 4.73 and 6.91, respectively. In the study of Menesatti et al., 2014 the correlation coefficient between observed and predicted weight using body length, withers height and chest depth measurements taken by the web-camera system was found as 0.7946 . The study of Akkol et al. (2017) tried to predict live body weight by means of body measurements like chest width, rump height, withers height, back height, chest depth, chest girth and body length with the artificial neural network (ANN) and multiple linear regression (MLR) models. The $\mathrm{R}^{2}$, RMSE and MAPE values of the models estimated as, 89.8\%-91\%, 3.84-4.10, 4.80-4.90 for ANN models and $88.4 \%, 3.79$ and 4.87 for MLR model. Based on the all age group of Highland sheep, heart girth and body length was found enough to estimate body weight with $\mathrm{R}^{2}=73 \%$ in the study of Tadesse and Gebremariam, 2010. The $\mathrm{R}^{2}$ value of the FES developed by Taşdemir et al., 2011 for predicting LBW of Holstein cows with the inputs like wither height, hip height, body length and hip width was estimated as $98 \%$. 


\section{Conclusions}

In this study, 81 experimental data were used to estimate live body weight, with linear body measurements (heart girth, body depth and body length). Experimental data were compared with results obtained with the fuzzy expert system. It was observed that the designed FES results were highly correlated with the experimental data and $90 \%$ was confirmed. Much better results can be obtained in the subsequent studies with increasing the number of input and output parameters and the number of linguistic variables.

The usage of FES modeling may be highly recommended to predict LBW instead of time consuming experimental studies.

Acknowledgements. This study is a part of an Ms. thesis and is supported with project no 2016-Sİ̈̈FEB21 by Siirt University Coordinator of Scientific Research and Projects.

\section{REFERENCES}

[1] Abegaz, S., Awgichew, K. (2009): Estimation of weight and age of sheep and goats. ESGPIP - Technical Bulletin (23), Ethiopia.

[2] Agbonifo, O. C., Ajayi, A. O. (2012): Design of a fuzzy expert based system for diagnosis of cattle diseases. - International Journal of Computer Applications \& Information Technology Vol. I(III): 93-98.

[3] Akkol, S., Ak1llı, A., Cemal, İ. (2017): Comparison of artificial neural network and multiple linear regression for prediction of live weight in hair goats. - Yüzüncü Yıl Üniversitesi Tarım Bilimleri Dergisi 27(1): 21-29.

[4] Alizadeh, H., Hasani-Bafarani, A., Parvin, H., Minaei, B., Kangavari, M. R. (2008): Dairy cattle judging: an innovative application for fuzzy expert system. - Proceedings of the World Congress on Engineering and Computer Science 2008 WCECS 2008, October 22 - 24, 2008, San Francisco, USA.

[5] Allahverdi, N. (2002): Uzman Sistemler. Bir yapay zeka uygulamas1 (Expert Systems. Application of an Artificial Intelligence). Atlas Yayın Dağıtım, İstanbul.

[6] Chacon, E., Macedo, F., Velázquez, F., Paiva, S. R, Pineda, E., McManus, C. (2011): Morphological measurements and body indices for Cuban Creole goats and their crossbreds. - R. Bras. Zootec. 40(8): 1671-1679.

[7] Dăg, B., Mammadova, N. M., Keskin, İ., Altay, Y., Topuz, D. (2015): Developing expert systems based on fuzzy logic in dairy cattle husbandry. - Conference: The $1^{\text {st }}$ Mitrovica Innovations Scientific International Conference - MISIC 2015.

[8] FAOSTAT (2016). http://www.fao.org/faostat/en/\#data/QA/visualize.

[9] Ferreira, L., Yanagi-Jr, T., Nääs, I. A., Lopes, M. A. (2007): Development of algorithm using fuzzy logic to predict estrus in dairy cows: Part I. - Agricultural Engineering International: the CIGR Ejournal. Manuscript IT 06 004. Vol.IX: 1-16.

[10] Graybill, F. A., Iyer, H. K. (1994): Regression Analysis: Concepts and Applications. Duxbury Press, USA.

[11] Iqbal, Z. M., Javed, K., Abdullah, M., Ahmad, N., Ali, A., Khalique, A., Aslam, N., Younas, U. (2014): Estimation of body weight from different morphometric measurements in Kajli lambs. - Journal of Animal and Plant Sciences, 24(3):700-703.

[12] Jampour, M., Champour, M., Ashourzadeh, M., Yaghoobi, M. (2011): A fuzzy expert system to diagnose diseases with neurological signs in domestic animal. - Conference: Eighth International Conference on Information Technology: New Generations, ITNG 2011, Las Vegas, Nevada, USA.

[13] Keskin, I., Dağ, B. (2006): Comparison of different mathematical models for describing the complete lactation of Akkaraman ewes in Turkey. - Asian Aust. J. Anim. Sci. 19: 
$1551-1555$.

[14] Mahmud, M. A., Shaba P., Zubairu, U. Y. (2014): Live body weight estimation in small ruminants - a review. - Global Journal of Animal Scientific Research 2(2):102-108.

[15] Mamdani, E. H., Assilian, S. (1975): An experiment in linguistic synthesis with a fuzzy logic controller. - International Journal of Man-Machine Studies 7(1): 1-13.

[16] Mason, I. L. (1996): A world dictionary of livestock breeds, types and varieties, 4th edition. CAB International, Wallingford, UK.

[17] Menesatti, P., Costa, C., Antonucci, F., Steri, R., Pallottino, F., Catillo, G. (2014): A lowcost stereovision system to estimate size and weight of live sheep. - Computers and Electronics in Agriculture. 103: 33-38.

[18] Nabiyev, V. (2005): Yapay Zeka, Problemler-Yöntemler-Algoritmalar (Artificial Intelligence, Problems-Methods-Algorithms), Seçkin Yayıncilık, Ankara.

[19] Negnevitsky, M. (2005): Artificial Intelligence. A Guide to Intelligent Systems. www.pearson-books.com. CPearson Education Limited, Essex, England.

[20] Olfaz, M., Tozlu, H., Onder, S. (2011): Effect of hair colour variation on milk production and kid growth in Turkish Hair goat. - J. Anim. Vet. Adv. 10: 1037-1040.

[21] Pesmen, G., Yardimci, M. (2008): Estimating the live weight using somebody measurements in Saanen goats. - Archiva Zootechnica 11(4): 30-40.

[22] Riva, J., Rizzi R., Marelli, S., Cavalchini, L. G. (2004): Body measurements in Bergamasca sheep. - Small ruminant research 55: 221-227.

[23] Sowande, O. S., Sobola, O. S. (2008): Body measurements of west African dwarf sheep as parameters for estimation of live weight. - Trop. Anim. Health Prod.. 40(6): 433-439.

[24] Tadesse, A., Gebremariam, T. (2010): Application of linear body measurements for live body weight estimation of highland sheep in Tigray region, North-Ethiopia. - Journal of the Drylands 3: 203-207.

[25] Taşdemir S., Ürkmez, A., İnal, Ş. (2011): A fuzzy rule-based system for predicting the live weight of Holstein cows whose body dimensions were determined by image analysis. - Turk J Elec Eng \& Comp Sci. 19(4): 689-703.

[26] Yilmaz, O., Kor, A., Ertugrul, M., Wilson, R. (2012): The domestic livestock resources of Turkey: Goat breeds and types and their conservation status. - Animal Genetic Resources/Ressources Génétiques Animales/Recursos Genéticos Animales 51:105-116. 